\title{
Effective Comprehension Instruction At The Pre-Service Level
}

Lynne Mills, Auburn University Montgomery, USA

Jan Hogan, Auburn University Montgomery, USA

\begin{abstract}
A higher education development team consisting of four professors of reading at two universities designed a set of lessons for possible use in helping teachers or preservice teachers develop strategies to produce effective comprehension skills of elementary students. These techniques were first used with undergraduate candidates and then revised to use with reading coaches in the literacy demonstration sites around the state of Alabama. The author describes a set of four interventions based upon this work that was used with graduate preservice teachers in a reading methods course. Three areas were emphasized in this investigation: changing preservice teachers' misconceptions about the meaning of comprehension, helping them understand what readers do to comprehend text, and teaching them how comprehension can be explicitly taught to elementary students. Through these interventions, the preservice teachers gained a better understanding of how to teach comprehension more effectively to $K-6$ students.
\end{abstract}

Keywords: teacher education, reading instruction, explicit comprehension instruction, elementary education, professional development for reading teachers

\section{INTRODUCTION}

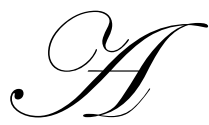

$s$ teacher educators, it is imperative that we explore new ways to help our teacher education candidates become more effective reading instructors. One area of particular interest revolves around helping pre-service teachers develop strategies to produce effective comprehension skills of their elementary students. The first obstacle we face in this endeavor is to dispel pre-service teachers' long-held beliefs about comprehension instruction. Unfortunately, as students, they participated in many comprehension activities throughout their years of schooling, but it is unlikely that many of them were ever actually aided in their comprehension skills as a result of this type of instruction. Just as Richard Allington (2006) asserts "school tasks . . . traditionally labeled as comprehension tasks have largely focused on remembering, a very narrow slice of what is needed for understanding what we read" (p. 115). It is impossible to understand without remembering. However, it is possible to remember something without understanding it. Unfortunately, most school comprehension instruction emphasizes remembering instead of "thoughtful consideration and discussion of text" (Allington, p. 115).

The following investigation was aimed at discovering how to best make changes in pre-service teachers' instructional practices in a field experience. It came about from the work of a higher education development team consisting of four professors of reading at two universities. The team was led by Dr. Susan Villaume at Auburn University as part of the work of the Alabama Reading Initiative (ARI) Collaborative. The ARI Collaborative was comprised of higher educators from eight universities, state department personnel, and reading coaches who worked with the literacy demonstration schools in the state. Representatives from these three components met monthly to study reading instruction and how to make changes in the reading progress of K-12 students through effective professional development of teachers. The fifty participants of the ARI Collaborative alternately served on a development team to research and plan for specific topics of study every month. This investigation originated with the work conducted as a member of such a team.

Much of the work of the development team was centered on how to help pre-service teachers understand explicit comprehension instructional strategies. The team conducted several activities with two undergraduate 
reading classes at two universities before sharing the findings with the ARI Collaborative. The ARI Collaborative members were then asked to take these ideas, revise them, and use them in a monthly regional reading coach training session. The monthly training sessions were designed to teach the reading coaches techniques to use with the teachers in their respective schools. Therefore, ultimately the same techniques designed by a development team of the ARI Collaborative were used with pre-service teachers in state universities and regional and state reading coaches, who then shared what they learned with the teachers in the literacy demonstration schools around the state.

After revising the techniques used with the undergraduate classes and the ARI Collaborative, the author was anxious to try them with her graduate reading class. The eleven non-traditional graduate students majoring in elementary education (with undergraduate degrees in other areas) and no teaching experience were chosen by the instructor to participate in the investigation. Of course, inservice teachers enrolled in the course were provided the opportunity to participate in the activities but not be involved in the investigation.

In the beginning of the investigation the participants were asked to describe their understanding of comprehension in general, including what they perceived to be interferences with comprehension. Then they were asked to describe comprehension strategies from a skillful reader's perspective and comprehension instructional strategies from a teacher's perspective. Their responses were analyzed and placed into three categories: definition of comprehension (including interferences to comprehension), comprehension strategies used by skillful readers, and comprehension instructional strategies used by teachers.

\section{Definition of Comprehension}

In the beginning eight of the participants out of eleven described comprehension as "understanding what you read". This shows they had a basic understanding of the term, even though quite general in nature. The most important aspect of this response is that three participants had no knowledge of how to explain comprehension, which shows they have no basis of how to explain the process to their prospective students.

Some participants showed they had some basic knowledge of interferences readers have when comprehending, but the knowledge was limited. Four of the participants stated that if one didn't have prior knowledge it made it difficult to comprehend, which shows an understanding that if readers have a problem with the system of meaning they would have problems comprehending. Three participants made comments concerning the system of print as being an interference. They stated that if the words were too hard then comprehension would be difficult or if a reader wasn't fluent then he would have problems. Two participants stated that it was possible to read all the words well without comprehending, which shows they have some knowledge that it is possible to have interferences with things other than the system of print and still not be able to comprehend. Two participants also stated one had to pay attention to comprehend or had to be interested in what he/she was reading, which shows they have an understanding of how disposition plays a role in comprehension. No one mentioned language as a possible interference. Therefore, it was ascertained that the majority of participants had very little knowledge of the interferences readers have when they are trying to comprehend text.

\section{Comprehension Strategies of Readers}

This component of the investigation was crucial according to the research. Pressley (2001) found if teachers begin to identify and understand comprehension strategies themselves then they have a better understanding why it is so important to teach these strategies to their students.

Four participants out of eleven made comments related to an understanding of what a skillful reader does to comprehend more effectively. Two participants said a reader may have to reread to comprehend. One participant said a reader should read for key points. Another stated a reader might ask himself a question, "What is going on?" or look at picture cues to comprehend. Another mentioned how discussing what one reads with someone else helps comprehension. However, the vast majority of participants had very little knowledge of particular comprehension strategies skillful readers use when reading text. 


\section{Comprehension Instructional Strategies of Teachers}

When it came to an understanding of how teachers should teach comprehension the most common answer (7 out of 11 participants) was that teachers should check comprehension by asking questions or have the students respond in writing by retelling or summarizing what they read. One participant mentioned discussion was a way to see if children had comprehended but it was implied that comprehension was to be checked, not really taught. This response is not surprising, considering what the research states about comprehension instruction in most classrooms and what the average adult has experienced in school over the years.

Research conducted throughout the last decade has pointed out that there are some strategies are crucial in developing more effective comprehension skills of a reader. These strategies are: activating prior knowledge, summarizing, story grammar lessons, imagery, question generating, and thinking aloud. Furthermore, it seems to be beneficial to make these comprehension strategies visible to the struggling reader. However, it is important to integrate these strategies instead of using them in isolation (Allington, 2006). It is difficult to teach multiple strategies to pre-service teachers who don't have some idea of specific strategies good readers employ. Therefore, the author chose to label specific strategies for the participants in the beginning, while emphasizing how readers use them in combination.

\section{Intervention One}

First, the instructor presented an overview of the five areas of effective reading instruction according to the research: comprehension, phonemic awareness, phonics, fluency, and vocabulary. All of the areas had been previously discussed, except comprehension. The following important points were made.

1. Comprehension is the reason for reading.

2. Comprehension is important to beginning readers, as well as more experienced readers.

Then, a status report was presented to the participants concerning the research on comprehension instruction according to the National Reading Panel (NRP, 2000). The main focus of this discussion was on the following three ideas.

1. Children can read well in the primary grades and still not become effective comprehenders in the intermediate grades.

2. Many teachers spend a great deal of time assessing comprehension and rarely teach how to do it.

3. Very few teachers really understand comprehension instruction because they have no professional development in this area.

The participants were asked to talk with a partner and summarize why we need to be concerned with this research. Then, the instructor presented the definition of comprehension as given in the 2000 NRP report. The definition is, "Reading is purposeful and active. Meaning resides in the intentional, problem-solving, thinking processes of the reader that occur during an interchange with a text. The content of meaning is influenced by the text and by the reader's prior knowledge that is brought to bear on it" (NRP, 2000, pp. 4 -39).

The participants individually underlined the most important word in each sentence of the definition and explained to a partner why they underlined those words. A small group discussion followed by a large group discussion brought out these points. The words identified as being the most important were: "purposeful", "problem-solving", and "reader's prior knowledge". The instructor of the course had to help the participants understand how the meaning of the text influences the reader ("interchange", "to bear"). Most of the participants understood what the reader had to bring to the text, but did not have a clear idea of how the text also brings something to the reader.

Then, the participants were given a very short passage that had an unclear meaning to read and discuss with their small group. Much conversation occurred around the meaning of the passage and finally, the group was ready to discuss specific comprehension strategies they used to build meaning. A short list of comprehension strategies 
was generated from this discussion. The list was: imagery, question generating, rereading for clarification, and sharing ideas with others. The list was not meant to be exhaustive at this point. However, the important thing was for the participants to begin to understand the different things they do when they comprehend. In keeping with the research, the instructor ensured the participants understood that these strategies were used in combination and interchangeably, not in isolation.

\section{Intervention Two}

During the next class meeting the list was reviewed and a new passage was presented in order for the participants to understand how to slow down their thinking and analyze deeply how they comprehend. A short story was used for this exercise. The instructor told the participants to fold their papers in such a way so that only the title of the piece was visible. The instructor modeled what she was thinking about the title. She made predictions and asked questions. Then, the participants were allowed to move the papers down to uncover the first few lines. They were asked to give their thoughts to the whole group about what they were thinking at this point. The text was divided in two additional sections and the participants were to make notes about what they were thinking at the end of each section of the piece. These notes were to teach them how to track their thinking while they read. Even though it was very difficult for fluent readers to slow down the process, the participants began to understand what was going on in their minds as they struggled to comprehend the text. New strategies were added to the original list. The new words were: predicting, inferring, and analyzing.

After this experience the participants were asked to look at common interferences to reading comprehension and discuss the interferences they had, even as fluent readers. Most of their interferences dealt with the system of meaning or lack of prior knowledge of some of the ideas in the text. However, there was one interference in the system of language and the instructor was quick to bring it to the forefront. Then, the class was told to think about younger readers and the interferences they might have. Disposition was discussed and how someone's attitude might not be right for continuing to reread to build understanding of this text. Also, discussion centered on how younger readers might have interferences in the system of print (accuracy, automaticity, and fluency).

The last activity followed strategy instruction endorsed by Roehler and Duffy (1984), where readers think about texts together. The instructor explained the comprehension strategy, modeled the strategy by thinking aloud, and offered the opportunity for the participants to practice the strategy with guidance from the instructor. This type of instruction has many benefits because it not only teaches the participants how readers comprehend through explicit instruction, it provides a model with which they can then use with children they teach.

A model simulation lesson was conducted. The instructor asked for four volunteers to pose as first graders. She began the model simulation by assigning the other class members to take notes on what they noticed about how the lesson was taught. After the four volunteers took their seats at the reading table the instructor asked them to pretend that they had already learned the comprehension strategies of "making predictions" and "question generation" in the months prior to this lesson. Tonight the model teacher would be working on "making inferences". The words "infer", "inferring", and "making inferences" were written on the chart and briefly discussed. Then, the instructor told the group to pretend one child asked another child to spend the night with her. The children were asked if they would ask any questions or make predictions if that happened to them. One child asked, "Would I be able to bring my mama?" and another predicted they would be eating French fries because they always ate French fries at that house. The instructor offered an inference that the caller must really like the other child. The point was made that the caller never said such a thing and how the instructor inferred it. Then, the children were asked to make predictions and generate questions as they looked at the cover of the book the instructor would be reading aloud. The instructor offered an inference about the feelings of the character in the book based upon how the character's face looked. As the instructor read the book to the children she mentioned the inferences she was making. If a child offered something to the discussion, the instructor labeled the statement for the child by saying, "That's a good prediction (question or inference)." After the instructor finished the book the children were told to think about the inferences they make as they read throughout the week. 
After the simulation lesson the entire class of pre-service and inservice teachers shared what they had noticed about how it was taught. The learning model (explanation, modeling, guided practice, and application), patterned from the explicit instruction model of Rosenshine (1983), was discussed as it related to this lesson. The group identified specific techniques that were used by the instructor. It was explained that even though one comprehension strategy was emphasized in the lesson, other comprehension strategies used by the children were acknowledged to reinforce the idea that multiple strategies are needed to fully comprehend the text, not just one.

\section{Intervention Three}

The following week another model lesson was conducted with an expository text that was similar to what fifth graders would be expected to read in a social studies textbook. The skill that was targeted was "clarification." A reading coach with the Alabama Reading Initiative began the lesson by pulling four volunteers from the class to serve as fifth graders. The rest of the class was instructed to take notes on how the lesson was conducted. She began the lesson by discussing the word "clarification". The students were told it is when you ask yourself if what you are reading makes sense. Then, she modeled how she gained clarification about a personal situation in her life. The example she used revolved around her sixteen-year-old asking to go to a football game on Friday night. Her son had told her he would need to check out of school early to go and asked permission to do so. She placed four questions on the board. The questions were: Do I understand the words? Is there any information that doesn't agree with what I know? Are there any ideas that don't fit together? Is there any information that is missing or not clearly explained? She led the students to answer each question with her example. Then, she moved to the expository text. She read the title and the introduction aloud as the students followed in their text. She went over the questions above again and related it to the text. She pointed out words she had trouble understanding and asked the students to suggest what she might do to help clarify their meanings. Then, she discussed her prior knowledge about the subject and how it compared to what she was reading in the introduction by pointing out things that didn't agree with what she knew, ideas that didn't fit together, and unclear statements. The students agreed that "rereading" and "reading on" might solve some of these clarification issues. Then, she asked the students to read the next section. Again, the questions used previously directed the discussion. Any ideas that were clarified by "reading on" were mentioned. At the end of the lesson, the students were asked to use the new strategies they had learned to read the rest of the chapter. Before the end of class the instructor led the class in another follow-up discussion on the notes the class took about the structure of the lesson.

\section{Intervention Four}

The participants were introduced to graphic organizers and how they might be used with elementary students as instructional tools and scaffolds for thinking about text meaning. A sample text was passed out to each small group and one sample graphic organizer was randomly given to each participant in each group. The participants were to think about how to use the graphic organizer with the particular text and how it could be used as an instructional tool for a particular comprehension strategy. Then, the participant had to explain to his/her small group what he/she discovered about the graphic organizer.

\section{RESULTS}

Three areas were used for assessment purposes. The participants were asked to write about comprehension instruction again, just as they had done at the beginning of the investigation to be used as a post-test. The instructor compared lesson plans turned in by the participants before and after intervention instruction to ascertain if any of the ideas had been implemented in the field. The instructor also observed each of the participants teach one lesson to elementary students and noticed if and how comprehension was taught to these children.

\section{Definition of Comprehension}

It was revealed on the post-test that all of the participants had an understanding of the definition of comprehension and the interferences readers have when comprehending. 


\section{Comprehension Strategies of Readers}

There was a marked difference between the comprehension strategies mentioned by the participants on the pretest and the post-test. Table 1 summarizes the responses.

Table 1: Comprehension Strategies Readers Use

Pre-service Teachers' Responses Number of Participants Who Answered Accordingly (n=11)

\begin{tabular}{|c|c|c|}
\hline & Pretest & Post-test \\
\hline Rereading & 2 & 11 \\
\hline Forming mental pictures & 0 & 9 \\
\hline Asking questions as they read & 1 & 9 \\
\hline Analyzing text & 0 & 8 \\
\hline Making inferences & 0 & 8 \\
\hline Making predictions & 0 & 7 \\
\hline Making connections to self, text, and world & 0 & 6 \\
\hline Evaluating text & 0 & 6 \\
\hline Synthesizing text & 0 & 5 \\
\hline Summarizing text & 0 & 4 \\
\hline Reading on & 0 & 4 \\
\hline Clarifying text & 0 & 3 \\
\hline Self-monitoring and varying pace & 0 & 2 \\
\hline Sharing with others & 1 & 0 \\
\hline Looking at pictures in text & 1 & 0 \\
\hline
\end{tabular}

\section{Comprehension Instructional Strategies of Teachers}

There was a marked difference between the results on the pretest and post-test. In general, the participants realized that testing comprehension was not synonymous with teaching it. More of the participants had knowledge of various techniques used to teach comprehension than before the intervention classes. Table 2 summarizes the responses.

Table 2: Instructional Strategies to Teach Comprehension Pre-service Teachers' Responses Number of Participants Who Answered Accordingly (n=11)

\begin{tabular}{|l|c|c|}
\multicolumn{2}{c|}{ Pretest } & Post-test \\
\hline Test to see if it has occurred & 7 & 0 \\
\hline Use graphic organizers & 0 & 7 \\
\hline Model strategies good readers use & 0 & 3 \\
\hline Teach multiple strategies, not one & 0 & 2 \\
\hline $\begin{array}{l}\text { Use metacognition (have students think about their } \\
\text { thinking as they comprehend) }\end{array}$ & 0 & \\
\hline
\end{tabular}

\section{Field Experiences}

The participants were required to conduct ten guided reading lessons with elementary students in a field situation. The instructor read reflections of nine of those lessons and observed one lesson at the end of the semester. She made notes of any effective comprehension strategies utilized by the participants. There was evidence that the participants included more graphic organizers in their lessons and stopped emphasizing the testing aspect of comprehension after the intervention sessions. However, no one attempted to use a lesson modeled for them in the intervention sessions with their elementary students. 


\section{DISCUSSION}

There was a dramatic increase in the level of the pre-service teachers' understanding of the strategies skillful readers use to comprehend more effectively. Their responses were more specific on the post-test and they used a wider variety of terms when explaining these two things. After analyzing the post-test results, it appears that the activities conducted in the first two and the last interventions were the most valuable. The pre-service teachers benefited greatly from thinking about their own thinking when they comprehended. A very high number of participants benefited from the model lesson on inferring with the mock group of first graders. However, the third intervention (clarification model lesson with expository text), while it may have reinforced what they learned in the previous two interventions, produced little or no new knowledge of comprehension strategies. Very few pre-service teachers mentioned anything covered in the last model lesson on the post-test. However, the knowledge gained from the first two interventions might not have made as much of an impact without the third intervention as reinforcement.

There was some increase in the level of the pre-service teachers' understanding of comprehension instructional strategies. The author believed the four interventions did introduce some instructional strategies to the participants but because the participants, only had the opportunity to use these strategies with elementary student for ten lessons and without any support directly in the field from the instructor, then it produced a limited level of understanding in this area. Richard Allington (2006) points out that the research collected over the last decade gives credence to the notion that comprehension instructional strategies can be explicitly taught to readers even though it takes time and repeated opportunities to practice those skills. Likewise, it would seem that it takes time and repeated opportunities for pre-service and inservice teachers to learn to teach these strategies. Another possible reason the pre-service teachers didn't use the strategies is because they are often consumed at this point in their career about managing behavior of students and following the procedures of a guided reading lesson plan than they are in perfecting their skills to impact student learning. It is the author's belief that more hands-on experiences under the direction of an expert would be needed to develop these instructional strategies to the level that would be acceptable.

\section{AUTHOR INFORMATION}

Dr. Lynne Mills is the Head of Early Childhood, Elementary, and Reading Education and Dr. Jan Hogan is an Assistant Professor in Elementary Education at Auburn University Montgomery in Montgomery, Alabama. They have been involved in reading education in the state for many years and have worked with teachers in the Alabama Reading Initiative (ARI) since its beginning in the state. Both were trainers for ARI reading coaches and have taught reading courses to teacher education candidates for many years.

\section{REFERENCES}

1. $\quad$ Allington, R. (2006). What really matters for struggling readers: Designing research-based programs. Boston: Pearson Education, Inc.

2. National Reading Panel. (2000). Report of the National Reading Panel: Teaching children to read. Washington, DC: National Institute of Child Health and Human Development.

3. Pressley, M. (2001, September). Comprehension instruction: What makes sense now, what might make sense soon. Retrieved from Reading Online: http://www.readingonline.org/articles/handbook/pressley/index.html

4. Roehler, L. R. (1984). Direct explanation of comprehension processes. In C. C. Duffy, L. R. Roehler, \& J. Mason (Eds.), Comprehension instruction: Perspectives and suggestions (pp. 265 - 280). New York: Longman.

5. Rosenshine, B. (1983). Teaching functions in instructional programs. The Elementary School Journal, 83 (4), 335 - 351. 


\section{NOTES}

